\title{
Prediction of Plate Crown during Aluminum Hot Flat Rolling by Finite Element Modeling
}

\author{
Evangelos Gavalas ${ }^{1,2}, *(\mathbb{D})$ and Spyros Papaefthymiou ${ }^{2}(\mathbb{D})$ \\ 1 ELKEME S.A. (Hellenic Research Center for Metals), 61st km Athens-Lamia Nat. Road, Oinofyta, \\ 32011 Viotia, Greece \\ 2 Laboratory of Physical Metallurgy, Division of Metallurgy and Materials, School of Mining \& Metallurgical \\ Engineering, National Technical University of Athens, Her. Polytechniou 9 str., Zografos, \\ 15780 Athens, Greece; spapaef@metal.ntua.gr \\ * Correspondence: egavalas@elkeme.vionet.gr
}

Received: 3 November 2019; Accepted: 26 November 2019; Published: 2 December 2019

check for updates

\begin{abstract}
The roll deflection during hot rolling can result in uneven thickness distribution across the width of a plate (crown). A conventional rolling mill is equipped with bending systems that can control this convex shape of the plate. However, the determination of the proper bending load is very complicated as the plate crown is influenced by the rolling conditions. In this paper, a thermo-mechanical Finite Element Model on LS-DYNA ${ }^{\mathrm{TM}}$ software was utilized to predict crown evolution based on the rolling conditions in order to determine the setting values for achieving the target crown. The simulation results were compared and verified with actual industrial data for rolling force, plate temperature and plate crown. This approach is essential for pass schedule design and process parameter optimization in order to achieve the desired product quality.
\end{abstract}

Keywords: Aluminum; FEM; hot rolling; LS-DYNA; crown; camber

\section{Introduction}

The increased demand for high strip shape quality of rolled aluminum flat products has led to various studies associated with the effect of rolling parameters on the strip's profile. In hot rolling, a plate is reduced in progressive steps from an initial thickness to final thickness. During this process, high forces develop between the strip and the work rolls, which result in roll deflection. The deflected rolls are not parallel to each other anymore, and the gap between the rolls is not perfectly rectangular but curved from the top and bottom side (work roll sides). The geometry of the roll gap is imprinted on the rolled strip resulting in uneven thickness distribution across the width called crown. More specifically, the center of the strip is thicker comparing to the edges. The rolls deflection due to separating force together with thermal expansion and wear of the rolls consist of the main factors that determine the final strip profile [1-3].

Most rolling plants utilize the same equipment for rolling a wide range of materials with various levels of mechanical properties, initial geometry of the plate and final specifications. As a consequence, the same pass schedule cannot satisfy the profile requirements of the different products. For this purpose, conventional 4-high rolling mills are equipped with hydraulic systems that allow the bending of the rolls in order to correct the strip's crown according to the required specifications. In most cases, the adjustment of roll bending is pre-specified for each pass schedule and relies heavily on the scheduler, the operator and the experience gained from previous pass schedules [4]. However, in a real production environment, the final crown depends on many factors and the correct bending force is difficult to be determined during the pass schedule design stage, let alone to be adjusted between the rolling passes. Nevertheless, some rolling mills are equipped with automatic roll bending actuators 
than either determining the bending set-point is of great importance or they require a lot of rolling data and training to define the bending set-point automatically, something that it is not suitable for production plants utilizing the same equipment for rolling a wide range of products.

In order to determine the process parameters, predictive analytical modeling has been an important tool and has been considered thoroughly [5-8]. Several models that calculate the bending force's influence on the plates' shape have been suggested by many researchers. Kang et al. [8] provided a model that considers the dependence of the strips' curvature on the velocity difference of the sides of the strip. Nandan et al. [4] identified both process parameters and pass schedule for optimum crown and flatness in hot rolling. Lee et al. [9] proposed a strip profile calculation model for a 6-high cold rolling mill based on the slab method, which considers the strip profile of the previous stand and includes the Hertz contact theory for the prediction of roll flattening. Steinboeck et al. [10] implemented an analytical model calculating the work roll bending based on nonlinear geometric relations, material derivatives, balance equations, constitutive equations for the material flow in the roll gap, and a change of coordinates to obtain a time-free formulation. Fukushima et al. [11] developed a model for predicting the strip profile with high accuracy and applied it to online control. The model was coupled with Finite Element Method (FEM) analysis that calculated the rolling load distribution. The utilization of this technology enabled the mixed rolling of products with substantial variation in mechanical properties. The computational cost of this method is low, but many assumptions have to be considered in the model, limiting the accuracy of the calculation results.

The other established modeling method is also based on FEM and has been widely employed by many researchers for rolling simulations, due to the increased quality of the results and the possibility to apply realistic boundary conditions and constraints in complicated models [12-18]. The method has been effectively applied for the prediction of strip crown in both cold and hot rolling operation. Gautam [19] correlated the deflection variation of a 2-high rolling mill with the reduction percent for different steel properties. Shigaki et al. [20] coupled a commercial FEM model with a Multi-Slab model for strip deformation in order to predict the roll stack deflection. Sun et al. and Linghu et al. $[3,14]$ employed an elastic-plastic FEM model to determine the work roll bending forces, intermediate roll bending forces and intermediate roll shifting on a CVC 6-High mill under certain rolling conditions for pass schedule strategy allocation. Chao et al. [4] used finite elements coupled with infinite elements to analyze the crown after introducing residual stresses into the strip.

In this work, a high accuracy 3D Finite Element Model (3D-FEM) was designed to study the effect of bending force on the final strip profile in the aluminum hot rolling process. Industrially used rolling parameters were used as input for the calculation, and the results can be used as set points during pass schedule design and as guidance for adjustment between different passes in a real production environment.

\section{Simulation Model}

The influence of the rolling parameters analysis was held on LS-DYNA software employing a 3D-FEM, as shown in Figure 1. For the rolls, the element size was $15 \mathrm{~mm}$ at the surface, and for the plate, the element size was $10 \mathrm{~mm}$ length- and width-wise. Thickness-wise the element size was $5 \mathrm{~mm}$ for the thick passes $(>15 \mathrm{~mm})$ and for the thin passes $(<15 \mathrm{~mm}) 3$ elements were the minimum number of elements, since a lower number had great variation in the final results. The simplified form of the equation of motion can be represented in the following form [12]:

$$
[m][\ddot{x}]+[c][\dot{x}]+[k][x]=[F],
$$

where $[m]$ is a mass matrix, $[c]$ is the damping matrix, $[k]$ is the stiffness matrix, $[x]$ is the displacement and $[F]$ is the applied force vector. Rolling is considered a quasistatic process, however, especially during heavy passes or when rolling speed is high both $[\dot{x}]$ and $[\ddot{x}]$ become significant. 
a)

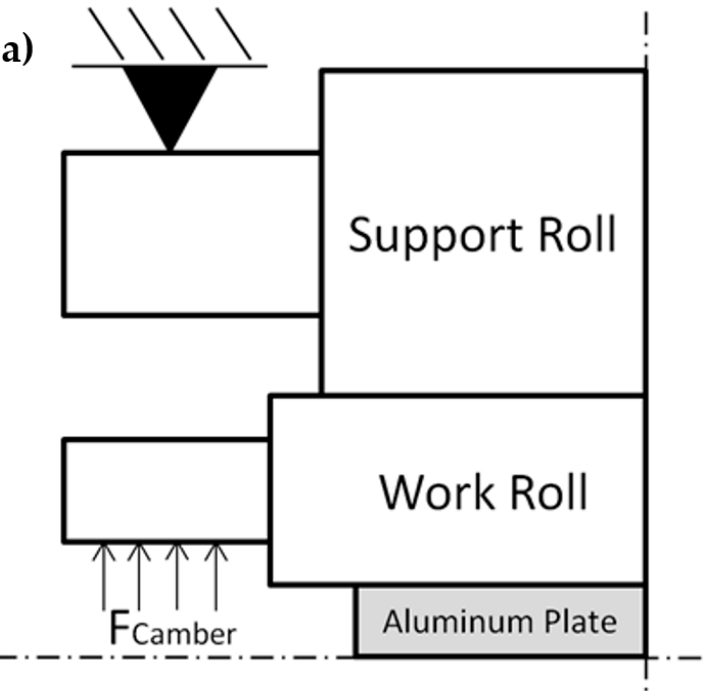

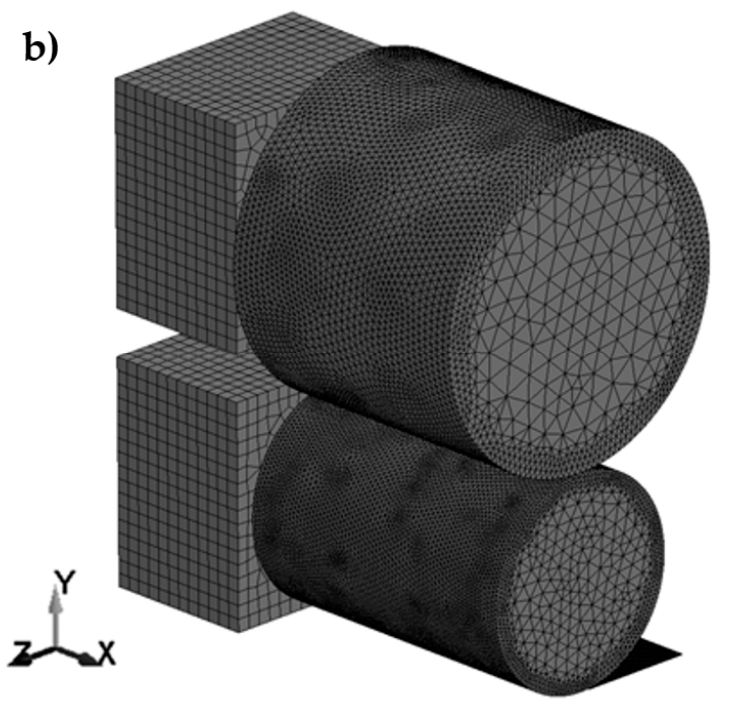

Figure 1. Schematic diagram of the (a) 4-high hot rolling mill, (b) 3D-FEM model.

The mill consists of a pair of work rolls and support rolls, mainly used to control the flatness of the rolled strip, and is equipped with a hydraulic system able to apply a bending load between the work rolls and between the work rolls and the support rolls. The work roll and support roll geometry are shown in Table 1. To minimize the overall computational cost, the system was considered as fully symmetric, and only one quarter of the complete model was simulated by setting two symmetry planes and the proper boundary conditions.

Table 1. Work and Support roll geometry.

\begin{tabular}{lc}
\hline Work Roll & Value \\
\hline Length $(\mathrm{mm})$ & 3000 \\
Diameter $(\mathrm{mm})$ & 950 \\
\hline Support Roll & \\
\hline Length $(\mathrm{mm})$ & 2500 \\
Diameter $(\mathrm{mm})$ & 1500 \\
\hline
\end{tabular}

Both steel rolls were modeled as elastic, while the 5754-O aluminum strip was modeled as elastic-viscoplastic utilizing the Johnson-Cook's constitutive equation [21]:

$$
\sigma_{\mathrm{f}}=\left(A+B \varepsilon_{p}{ }^{n}\right)\left(1+C \ln \dot{\varepsilon}_{\mathrm{p}}^{*}\right)\left(1-T^{*}\right)^{m},
$$

where, $\sigma_{\mathrm{f}}$ is flow stress, $A, B, n, C$ and $m$ are the Johnson-Cook material model coefficients, $\varepsilon_{p}$ is the equivalent plastic strain, $\dot{\varepsilon}_{\mathrm{p}}^{*}$ is the dimensionless plastic strain rate, and $T^{*}$ is the homologous temperature.

The Johnson-Cook material model is a strain, strain rate, and temperature-sensitive model, widely used in forming processes. The parameters used for both materials, as well as the physical and thermal properties are summarized in Tables 2 and 3, respectively.

The description of the contact between the roll and the strip requires the definition of the frictional conditions and the thermal properties. Literature values from similar set ups and mill/plate sizes were assumed in this work, which in most cases is concluded from iterative trial and error procedure in an industrial environment. 
Table 2. Roll and strip mechanical properties [21].

\begin{tabular}{lc}
\hline Aluminum Strip & Value \\
\hline Poisson's ratio & 0.33 \\
Young's modulus [GPa] & 70 \\
A [MPa] & 103 \\
$\mathrm{~B}[\mathrm{MPa}]$ & 296.6 \\
$\mathrm{C}$ & 0.4368 \\
$\mathrm{n}$ & -0.003101 \\
$\mathrm{~m}$ & 1.2451299 \\
\hline Steel Rolls & \\
\hline Poisson's ratio & 0.3 \\
Young's modulus [GPa] & 200 \\
\hline
\end{tabular}

Table 3. Roll and strip physical and thermal properties [22].

\begin{tabular}{lc}
\hline Aluminum Strip & Value \\
\hline Density $\left[\mathrm{Kg} / \mathrm{m}^{3}\right]$ & 2700 \\
Heat Capacity $[\mathrm{J} /(\mathrm{kg} \mathrm{K}]$ & 904 \\
Thermal Conductivity $[\mathrm{W} / \mathrm{m} \mathrm{K}]$ & 220 \\
\hline Steel Rolls & \\
\hline Density $\left[\mathrm{Kg} / \mathrm{m}^{3}\right]$ & 7800 \\
Heat Capacity $[\mathrm{J} /(\mathrm{kg} \mathrm{K}]$ & 485 \\
Thermal Conductivity $[\mathrm{W} / \mathrm{m} \mathrm{K}]$ & 38 \\
\hline
\end{tabular}

Two friction models are commonly used to describe the frictional condition in metal forming processes: The Coulomb's friction model and the shear friction model. As friction is a vast phenomenon to describe, both models sum all the mechanisms into a non-dimensional coefficient or factor [22].

$$
\tau_{\mathrm{f}}=\left\{\begin{array}{ll}
\mu \mathrm{p}, & \text { when } p<\frac{m}{\mu} \tau_{\mathrm{s}} \\
m \tau_{\mathrm{s}}, & \text { when } p>\frac{m}{\mu} \tau_{\mathrm{s}}
\end{array},\right.
$$

where $\mu$ is the coefficient of friction, $\mathrm{p}$ is the pressure, $m$ is the shear factor, and $\tau_{\mathrm{s}}$ is the shear yield stress. The frictional shear stress at low pressure is proportional to the normal pressure given by Coulomb's model. However, it equals the limited by $\mathrm{m}$ shear strength at high interface pressure.

The thermal boundary conditions in the contact between the strip and the roll strongly depend on specific conditions, such as the applied pressure on the roll, the surface roughness, the lubrication, the material, etc. An adequate designation of the thermal contact properties requires the definition of the conductance at the contact region and the convection to the air and the coolant.

$$
-\mathrm{k} \frac{\partial T}{\partial x}=h_{c}\left(T_{s}-T_{r}\right)-q_{f r i c}
$$

where $h_{\mathcal{c}}$ is the contact heat transfer coefficient, $T_{s}$ and $T_{r}$ are the strip and roll temperature, $q_{f r i c}$ is the generated energy, due to friction and $\mathrm{k}$ is the thermal conductivity [23]. The roll-strip interface conditions are summarized in Table 4 [22].

The material is reduced from a $660 \mathrm{~mm}$ thick slab to an $8.9 \mathrm{~mm}$ thin strip after several rolling passes. The initial conditions (roll speed, plate temperature, reduction percentage, etc.) are taken as input data from existing pass schedules. The temperature profile of the strip and the rolls are considered homogeneous at the beginning of each simulation step. Both separation force and temperature 
evolution were calculated in certain passes. Several simulations for the last pass were conducted varying the bending force. The crown is calculated as follows:

$$
\text { Crown }(\%)=\frac{t_{\text {middle }}-t_{\text {edge }}}{t_{\text {middle }}} \times 100,
$$

where $t_{\text {middle }}$ is the thickness of the strip at the middle width-wise and $t_{\text {edge }}$ the thickness at the edge of the strip.

Table 4. Roll and strip contact interface boundary conditions [22].

\begin{tabular}{lc}
\hline Frictional Boundary & Value \\
\hline coefficient of friction, $\mu$ & 0.4 \\
shear factor, $m$ & 0.8 \\
\hline Thermal Boundary & \\
\hline Heat Transfer Coefficient, $h_{c}\left[\mathrm{KW} / \mathrm{m}^{2} \mathrm{~K}\right]$ & 100 \\
\hline
\end{tabular}

\section{Simulation Results}

The prediction of crown development requires a validated simulation model, which is crucial for industrial practice. The separation force and the temperature are the two main factors that were compared and validated based on industrial data. The exact parameters of each pass and critical production data (e.g., rolling speed, pass schedule, etc.) were disclosed, due to confidentiality reasons.

\subsection{Force Calculation}

The rolling load development, according to the FEM simulation, is depicted in Figure 2. The specific rolling pass refers to a $34 \%$ reduction, from $6.7 \mathrm{~mm}$ entry thickness to $4.4 \mathrm{~mm}$ exit thickness and $550 \mathrm{~K}$ entry temperature to $510 \mathrm{~K}$ exit temperature. Once the strip comes into contact with the work rolls, the force rises until it reaches a steady state, where it remains almost constant. To indicate a specific value for the rolling force, the average of the highest and lowest value of rolling force was considered.

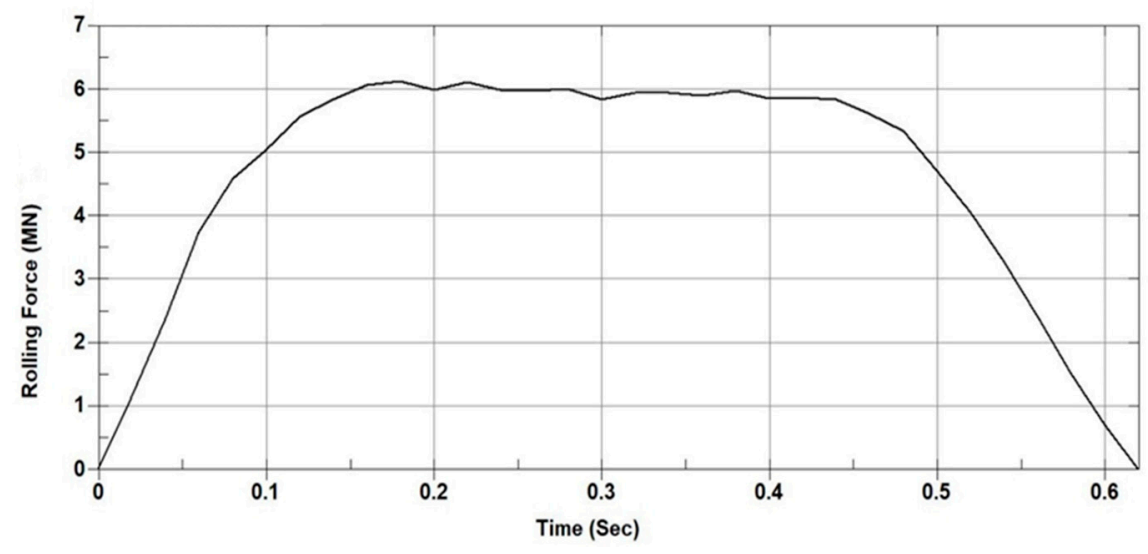

Figure 2. Simulated rolling force.

Indicative comparison of rolling force between the simulated and measured value for certain 10 passes of a pass schedule is shown in Figure 3. The procedure took place for different pass schedules before considering the model reliable for further utilization. The specific pass schedule refers to a final product of $1390 \mathrm{~mm}$ width and $600 \mathrm{~mm}$ starting thickness. The results of the validation process showed that the simulated values come into good agreement with the measured results, and the modeled can be considered as validated. 


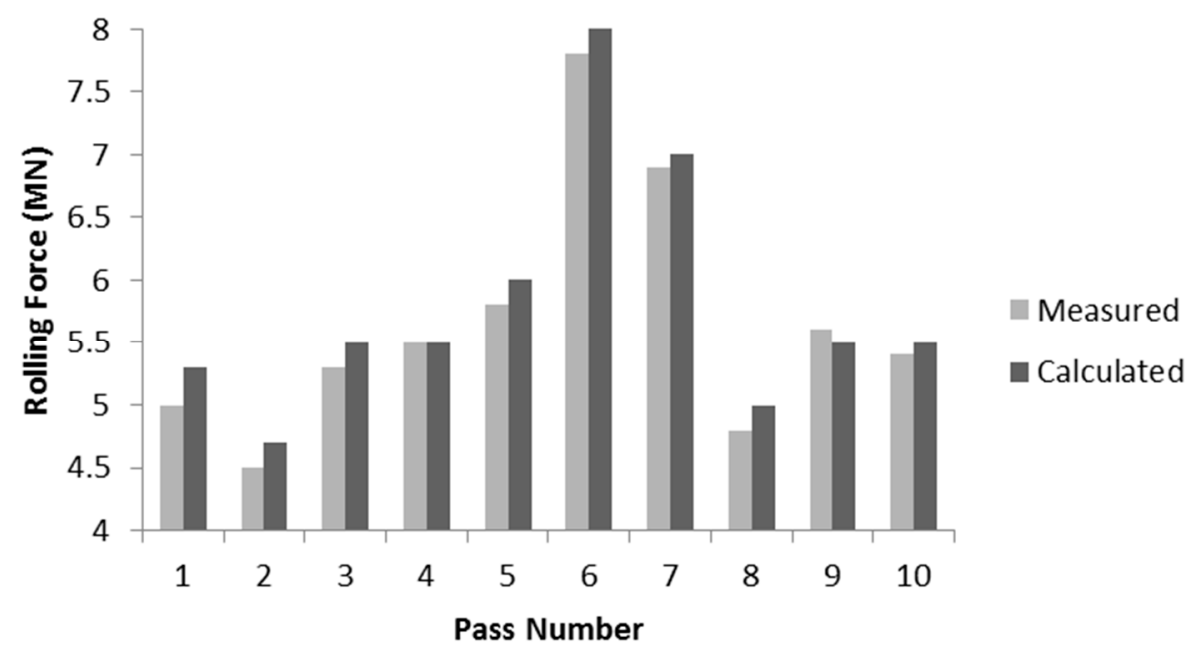

Figure 3. Comparison between measured and simulated separation force.

\subsection{Thermal Analysis}

The surface temperature was simulated for all the passes that were also used for the force validation. Indicative result of the last pass from a specific pass schedule is illustrated in Figures 4 and 5 and agree well with actual measurements taken during trials using an IR thermocamera (Figure 6). The comparison refers to the calculated and measured surface temperature after the required time for the strip to reach the measuring point, since the thermocamera is located several meters away from the roll bite.

The temperature distribution throughout the strip's thickness is illustrated in Figure 5. Temperature inhomogeneity can be observed through the thickness of the strip as it comes into contact with the roll, where heat is transferred from the strip's surface to the roll. Nevertheless, the temperature becomes uniform again shortly after the strip is disengaged from the mill. Temperature rise can be observed at the center of the strip, which can be attributed to the energy from the plastic deformation.

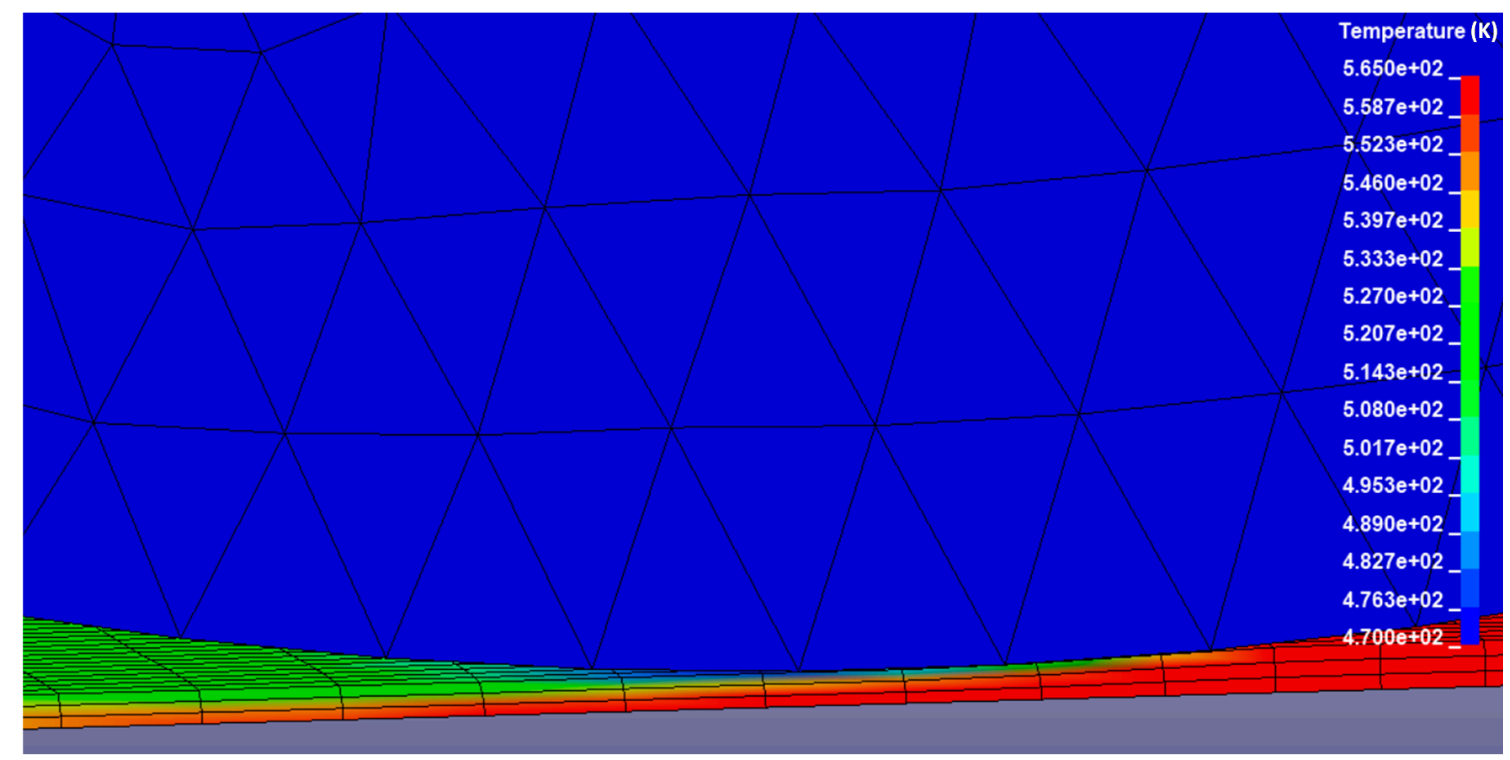

Figure 4. The temperature profile of the strip illustrated during the hot rolling process. 


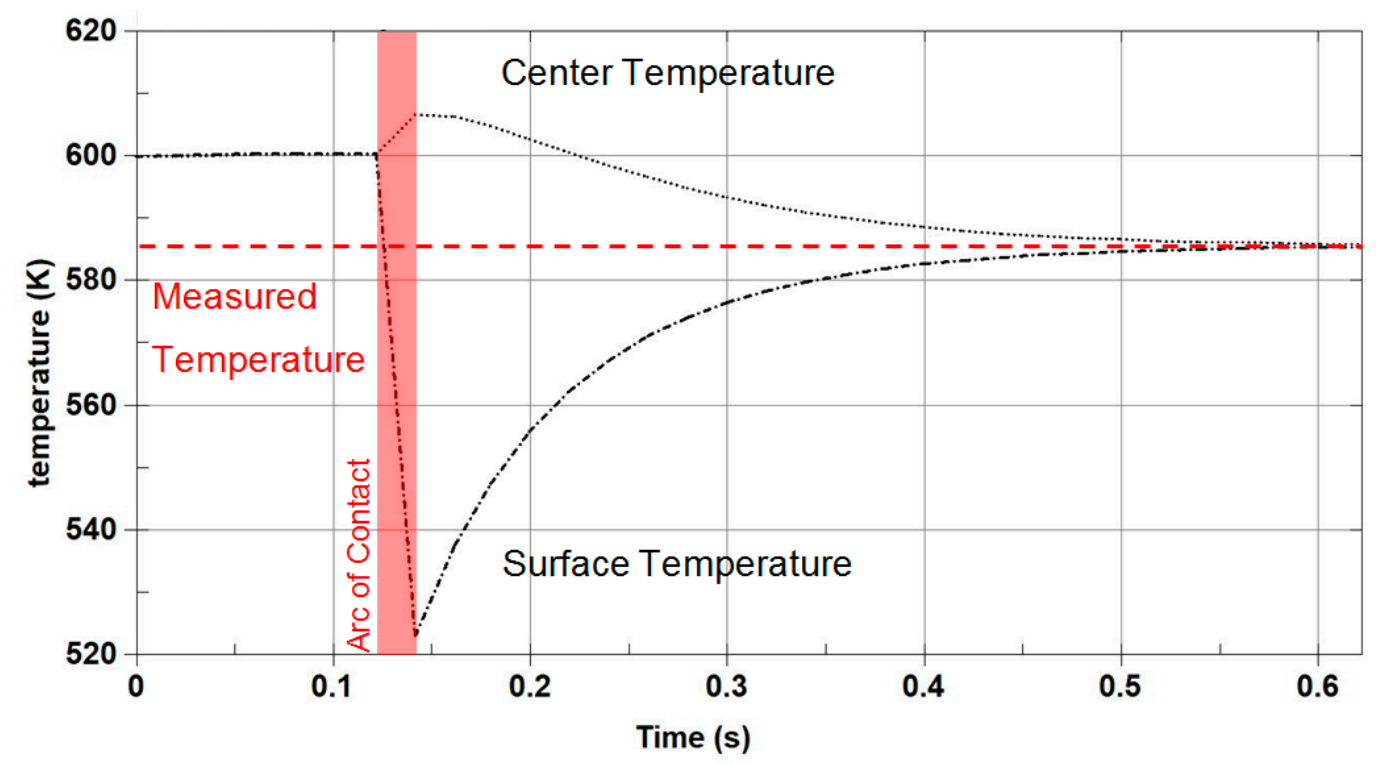

Figure 5. Temperature evolution on the surface and the center of the strip.

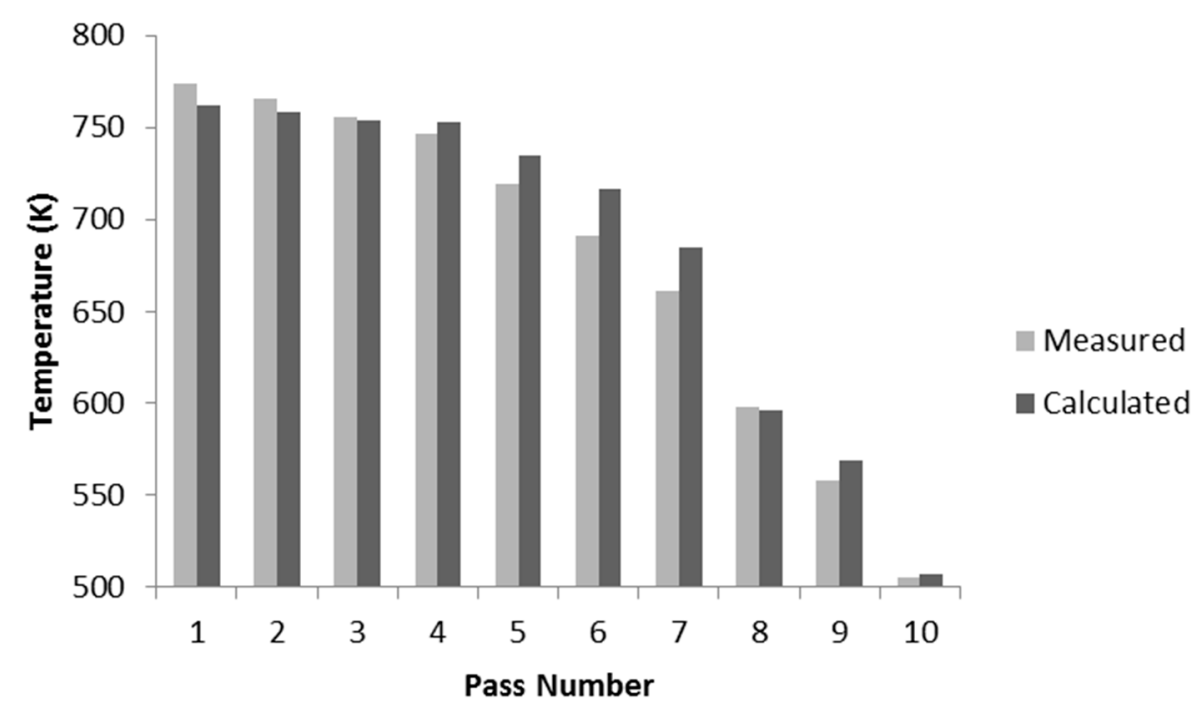

Figure 6. Comparison between measured and simulated temperature.

\subsection{Profile Prediction}

During rolling, the separation force causes the deflection of the rolls resulting in the final geometry of the strip not to be flat, but crowned, namely, the final thickness at the center of the strip is larger compared to the edges. Figure 7 depicts the influence of the bending force on the resulting strip's crown after the pass. The initial crown of the plate before this pass was $0.45 \%$.

The simulated crown was compared with crown deducted from the mills integrated crown measuring system for different passes (Figure 8). The mill's crown measuring system can be utilized only in the final passes of the pass schedule where the strips' thickness falls below a critical value $(<15 \mathrm{~mm})$ necessary for the device to work. 


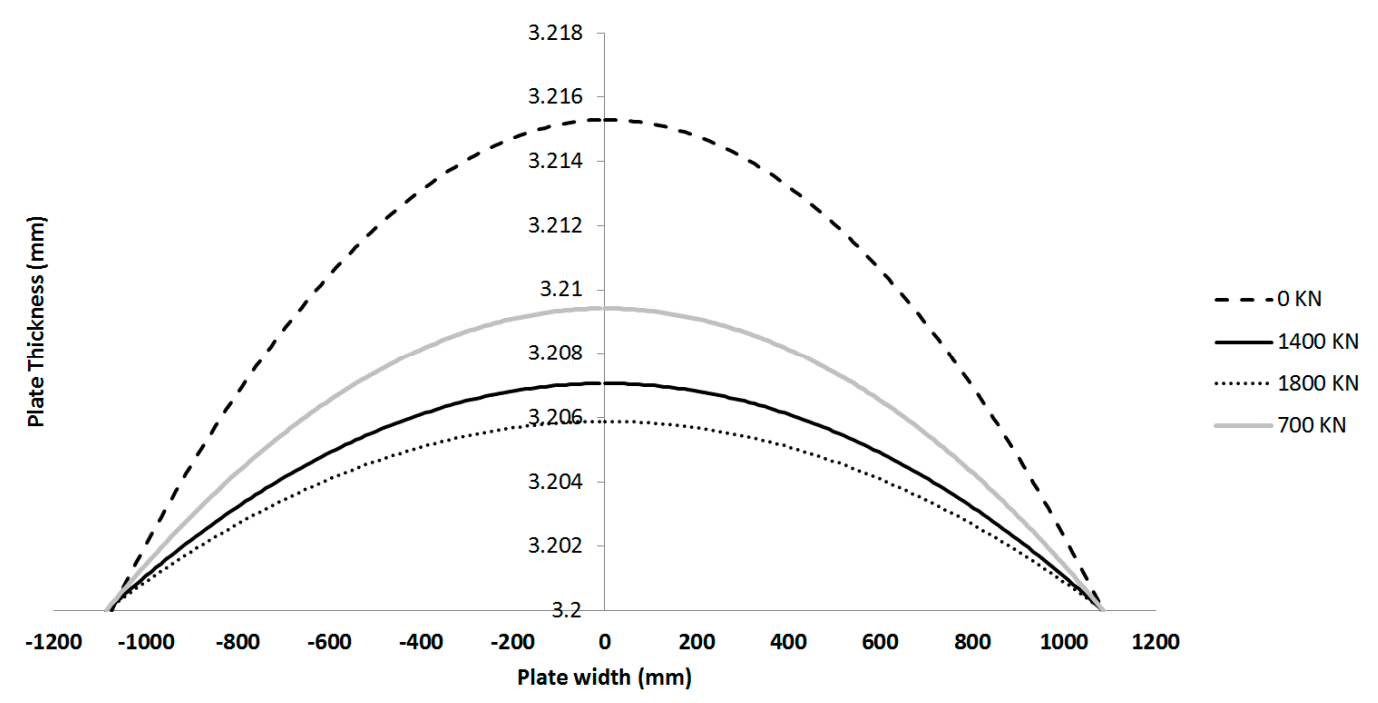

Figure 7. Influence of bending force on the plate's crown.

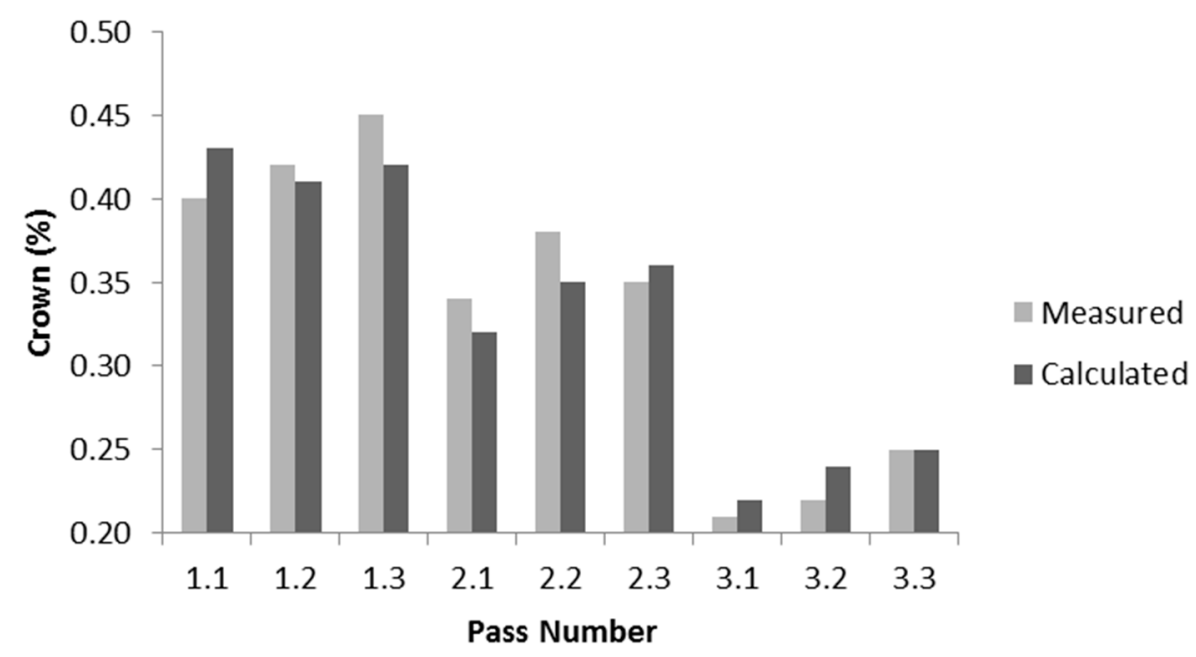

Figure 8. Comparison between measured and simulated crown.

\subsection{Discussion}

For accurate FEM model results, the formulation and the boundary conditions of the model have to be selected very carefully, and the input data must derive as much as possible from real measurements. The material model can greatly influence the simulation output. The Johnson Cook material model is a very efficient model based on the strain hardening law that also takes into account strain rate and temperature effects. Those types of models perform well in metal forming processes, when fitted for the correct temperature and strain range. However, in many cases, the temperature window is very narrow and influenced by recrystallization and recovery phenomena. In addition with large strains and when the temperature is well above the recrystallization point of the material, often saturation models, such as the voce model, become more efficient. Therefore, although the Johnson Cook yields good results in most cases on the pass schedule of the hot rolling process, validation is very important before used in passes, where the temperature and strain are high.

The pass schedule optimization is usually implemented according to "trial and error" methodology. This approach is restrictive due to the high cost of each trial, the limited information acquired from the mill and the empirical measures taken for the optimization. However, more importantly, it does not 
enhance the understanding of the material's and machine's behavior under specific conditions. For this purpose, the simulation approach, e.g., the Finite Element Method becomes essential. After validation, the FEM model provides important information and guidance for the pass schedule design with respect to profile and flatness optimization, better process parameter control and rolling mill throughput improvement (e.g., the geometry of the work and support roll). Moreover, process limitations and improvement possibilities can be identified more easily at an significantly lower cost.

In recent years quality is directly related to the consistent characteristics of the material. Heterogeneity can be introduced into the material from the hot rolling process, due to uneven temperature and plastic strain conditions. During the real process, these values cannot be measured, and the design is limited to the measurement of the surface temperature, characterization of the finished product and to the experience from different pass schedules. However, the temperature profile and local plastic strain are very important for the final microstructure. The data from the present thermo-mechanical model could be utilized as input data for a microstructural evolution model in order to simulate the resultant microstructure after the pass schedule.

In real industrial conditions, the crown measurement can only be performed during the last 2-4 passes by the mill's integrated measuring device. In case that the crown has big variation from the targeted value, it can sometimes be impossible to be corrected in the last passes or correcting it might introduce nonuniform stresses, especially during the last passes that in many pass schedules recrystallization is retarded. Thus, the crown must be controlled throughout the whole process, which can be implemented only through the precise prediction and design of the pass schedule.

Moreover, many parameters that influence the crown, e.g., the instantaneous geometry of the rolls, due to thermal expansion and wear, change dynamically. A common practice is the frequent replacement of the work rolls, due to its wear. However, regarding the crown evolution, due to thermal expansion, engineers strive to estimate the crown evolution and ensure that the whole length of the strip falls within the geometrical specifications despite the thickness variation. Even in the case that the mill is equipped with the automatic crown correcting system or the operator is skilled enough to correct the crown manually, it is very important to control the crown so that the bending system's operating window is enough to produce the desired result.

During hot rolling operations, the flatness actuators on the profile $\left(\mathrm{F}_{\text {camber }}\right)$ may be the most important direct influencing factors in order to control the crown evolution throughout the rolling process. Being able to predict the influence of the $\mathrm{F}_{\text {camber }}$ on the crown using a validated FEM model, provides valuable information for an optimized roll pass design.

\section{Conclusions}

In this work, a 3D—Finite Element Model using LS-Dyna software was presented for the prediction of plate crown during hot rolling. For the precise calculation of the process, the mechanical and physical material properties, the exact geometry of the rolling mill and the process parameters were considered. The obtained simulation results have been validated using trial measurements.

The calculated roll force and strip's temperature after each pass agree well with the industrially produced measurements.

The deflection of rolls at different passes can be controlled by applying the proper roll bending force. The strip profiles of the Finite Element simulation were similar to that of the real measurements.

The presented 3D-FEM model can predict the reliably the rolled strip profile and can be used as a tool for optimized roll pass schedule designs.

Author Contributions: Conceptualization, S.P.; Methodology, E.G.; Validation, E.G.; Writing-Original Draft Preparation, E.G.; Writing-Review and Editing, S.P.; Supervision, S.P.; Project Administration, E.G.

Funding: This research received no external funding.

Acknowledgments: The authors acknowledge the technical management of ELVAL S.A. for providing access to the production site and for the allowance to utilize production data for the validation of our model. The discussions with A. Mavroudis and D. Kortselis throughout the execution of the project are also highly appreciated. 
Conflicts of Interest: The authors declare no conflict of interest.

\section{References}

1. Liu, C.; He, A.; Qiang, Y.; Guo, D.; Shao, J. Effect of Internal Stress of Incoming Strip on Hot Rolling Deformation Based on Finite Element and Infinite Element Coupling Method. Metals 2018, 8, 92. [CrossRef]

2. Sato, M.; Kuchi, M. Profile and Flatness Set Up System for Rolling Mill. IHI Eng. Rev. 2009, 42, 26-31.

3. Sun, W.Q.; Li, B.; Shao, J.; He, A.R. Research on crown and flatness allocation strategy of hot rolling mills. Int. J. Simul. Model. 2016, 12, 327-340. [CrossRef]

4. Nandan, R.; Rai, R.; Jayakanth, R.; Moitra, S.; Chakraborti, N.; Mukhopadhyay, A. Regulating Crown and Flatness during Hot Rolling: A Multiobjective Optimization Study Using Genetic Algorithms. Mater. Manuf. Process. 2005, 20, 459-478. [CrossRef]

5. Cawthorna, C.J.; Loukaides, E.G.; Allwood, J.M. Comparison of analytical models for sheet rolling. Procedia Eng. 2014, 81, 2451-2456. [CrossRef]

6. Szúcs, M.; Krállics, G.; Lenard, J. A Comparative Evaluation of Predictive Models of the Flat Rolling Process. Periodica Polytech. Mech. Eng. 2018, 62, 165-172. [CrossRef]

7. Domanti, S.A.; Edwards, W.J.; Thomas, P.J.; Chefneux, I.L. Application of foil rolling models to thin steel strip and temper rolling. In Proceedings of the International Rolling Conference on Flat Products, Dusseldorf, Germany, 20-22 June 1994; pp. 1-8.

8. Kang, Y.; Jang, Y.; Choi, Y.; Lee, D.; Won, S. An Improved Model for Camber Generation During Rough Rolling Process. ISIJ Int. 2015, 55, 1980-1986. [CrossRef]

9. Lee, S.H.; Song, G.H.; Lee, S.J.; Kim, B.M. Study on the improved accuracy of strip profile using numerical formula model in continuous cold rolling with 6-high mill. J. Mech. Sci. Technol. 2011, 25, 2101-2109. [CrossRef]

10. Steinboeck, A.; Ettl, A.; Kugi, A. Dynamical Models of the Camber and the Lateral Position in Flat Rolling. Appl. Mech. Rev. 2017, 69, 040801. [CrossRef]

11. Fukushima, S.; Washikita, Y.; Sasaki, T.; Nakagawa, S.; Buei, Y.; Yakita, Y.; Yanagimoto, J. High-Accuracy Profile Prediction Model for Mixed Scheduled Rolling of High Tensile Strength and Mild Steel in Hot Strip Finishing Mill; NIPPON STEEL \& SUMITOMO METAL TECHNICAL REPORT No. 111; UDC 621. 771. 237. 016. 2: 62-523; Senior Researcher, Integrated Process Research Lab.: Kashima City, Japan, 2016.

12. Gavalas, E.; Pressas, I.; Papaefthymiou, S. Mesh sensitivity analysis on implicit and explicit method for rolling simulation. Int. J. Struct. Integr. 2018, 9, 465-474. [CrossRef]

13. Kapil, S.; Eberhard, P.; Dwivedy, S.K. Dynamic Analysis of Cold-Rolling Process Using the Finite-Element Method. J. Manuf. Sci. Eng. 2016, 138, 041002. [CrossRef]

14. Linghu, K.; Jiang, Z.; Zhao, J.; Li, F.; Wei, D.; Xu, J.; Zhang, X.; Zhao, X. 3D FEM analysis of strip shape during multi-pass rolling in a 6-high CVC cold rolling mill. Int. J. Adv. Manuf. Technol. 2014, 74, 1733-1745. [CrossRef]

15. Nakhoul, R.; Montmitonnet, P.; Legrand, N. Manifested flatness defect prediction in cold rolling of thin strips. Int. J. Mater. Form. 2015, 8, 283-292. [CrossRef]

16. Sherstnev, P.; Melzer, C.; Sommitsch, C. Prediction of precipitation kinetics during homogenisation and microstructure evolution during and after hot rolling of AA5083. Int. J. Mech. Sci. 2012, 54, 12-19. [CrossRef]

17. Simon, P.; Falkinger, G.; Scheiblhofer, S. Hot Rolling Simulation of Aluminium Alloys using LS-Dyna. In Proceedings of the 11th European LS-DYNA Conference, Salzburg, Austria, 9-11 May 2017.

18. Yoon, S.J.; Shin, T.J.; Lee, J.S.; Hwang, S.M. Three-Dimensional Finite Element Analysis of Skin-Pass Rolling and New Models for Process Control. J. Manuf. Sci. Eng. 2017, 139, 091003. [CrossRef]

19. Gautam, V. Finite element analysis of deflection of rolls and its correction by providing camber on rolls. Int. J. Res. Aeronaut. Mech. Eng. 2013, 1, 42-47.

20. Shigaki, Y.; Montmitonnet, P.; Silva, J.M. 3D finite element model for roll stack deformation coupled with a Multi-Slab model for strip deformation for flat rolling simulation. In Proceedings of the AIP Conference Proceedings, Dublin, Ireland, 26-28 April 2017; Volume 1896, p. 190018. [CrossRef]

21. Acar, D.; Türköz, M.; Gedikli, H.; Halkacı, H.S.; Cora, Ö.N. Warm Hydromechanical Deep Drawing of AA 5754-O and Optimization of Process Parameters. J. Eng. Mater. Technol. 2018, 140, 011012. [CrossRef] 
22. Couch, R.; Becker, R.; Rhee, M.; Li, M. Development of a Rolling Process. Design Tool for Use in Improving Hot Roll Slab Recovery; Lawrence Livermore National Laboratory: Livermore, CA, USA, 2004.

23. Bagheripoor, M.; Bisadi, H. Effects of rolling parameters on temperature distribution in the hot rolling of aluminum strips. Appl. Ther. Eng. 2011, 31, 1556-1565. [CrossRef]

(C) 2019 by the authors. Licensee MDPI, Basel, Switzerland. This article is an open access article distributed under the terms and conditions of the Creative Commons Attribution (CC BY) license (http://creativecommons.org/licenses/by/4.0/). 